ARTICLE OPEN

\title{
Quantitative evaluation of cement paste carbonation using
}

\section{Raman spectroscopy}

\author{
Tangwei Mi $\mathbb{1}^{1}$, Yongqiang Li ${ }^{1}$, Wei Liu' ${ }^{1}$, Weiwen $\mathrm{Li}^{1}$, Wujian Long ${ }^{1}$, Zhijun Dong ${ }^{2}$, Qianyi Gong ${ }^{2}$, Feng Xing ${ }^{1}$ and Yaocheng Wang $\mathbb{D}^{1 凶}$
}

Carbonation induced corrosion is one of the major durability issues for reinforced concrete structures. To address this issue, it is essential to understand the underlying mechanism of carbonation by detecting the ingress of the $\mathrm{CO}_{2}$ and carbonation depth quantitatively. This paper demonstrates the potential of Raman spectroscopy, as a powerful technique, to implement quantification analysis of cement paste carbonation. In present work, the correlation between the content of the $\mathrm{CO}_{3}{ }^{2-}$ and the Raman peak intensity was initially established by using several standard specimens premixed with certain amount of $\mathrm{CO}_{3}{ }^{2-}$. The established correlation was then used to investigate the carbonation of the cement paste in a $\mathrm{CO}_{2}$ diffusion scenario, and the results show a good agreement with that obtained by thermogravimetry measurements. Therefore, the feasibility of the Raman spectroscopy to quantify the carbonation degree of the cement paste can be demonstrated.

npj Materials Degradation (2021)5:35; https://doi.org/10.1038/s41529-021-00181-6

\section{INTRODUCTION}

As one of the major degradation types, carbonation of cement paste has attracted extensive attentions with attempts to understand the underlying mechanism. Portland cement is one of the most common construction materials around the world, benefiting from its excellent mechanical property and relatively well durability. Hydration of the Portland cement mainly produces portlandite $\left(\mathrm{Ca}(\mathrm{OH})_{2}\right)$ and other calcium-bearing phases like $\mathrm{C}-\mathrm{S}-\mathrm{H}^{1}$, which contributes to the development of the mechanical properties and alkalinity of the material. These properties would, however, be affected by the carbonation, which is one of the major degradation issues for cementitious material ${ }^{2}$. Essentially, the carbonation begins with the ingress of the $\mathrm{CO}_{2}$ into the pore solution to form carbonic acid which mainly reacts with $\mathrm{Ca}$ $(\mathrm{OH})_{2}$ (Reaction 1) and calcium-bearing phases (such as $\mathrm{C}-\mathrm{S}-\mathrm{H}$ (Reaction 2)) to form $\mathrm{CaCO}_{3}$, resulting in the neutralization of the alkaline environment ${ }^{3}$. The consumption of the hydroxides would certainly reduce the $\mathrm{pH}$ and potentially initiate corrosion of the steel reinforcement ${ }^{4,5}$. On the other hand, the precipitation of $\mathrm{CaCO}_{3}$ may form a denser structure than uncarbonated cement ${ }^{6}$. To assess the above effects, it is of great significance to precisely follow the carbonation evolution so that the carbonation induced corrosion and alteration of the mechanical property could be followed precisely. Thereby, development of a quantitative analysis technique is attracting increasing attentions.

$\mathrm{Ca}(\mathrm{OH})_{2}+\mathrm{CO}_{2} \rightarrow \mathrm{CaCO}_{3}+\mathrm{H}_{2} \mathrm{O}$.

(Reaction 1)

$\mathrm{C}-\mathrm{S}-\mathrm{H}+3 \mathrm{CO}_{2} \rightarrow 3 \mathrm{CaCO}_{3} \cdot 2 \mathrm{SiO}_{2} \cdot 3 \mathrm{H}_{2} \mathrm{O}$.

(Reaction 2)

To explore the carbonation evolution, several techniques have been well documented by former researchers, such as phenolphthalein indicator ${ }^{7,8}$, X-ray diffraction (XRD) ${ }^{9}$, thermogravimetric (TG) analysis ${ }^{10,11}$, and Infrared spectroscopy (IR spectroscopy) ${ }^{8,12}$. Spraying the phenolphthalein indicator on the carbonated cement is one conventional method to assess the carbonation depth ${ }^{8}$ and it is recognized as the most convenient method to capture the color change boundary between the carbonated and uncarbonated concrete where the $\mathrm{pH}$ is around $9^{13}$. Though phenolphthalein indicator is capable to give a continuous picture of the carbonated and uncarbonated zone, it can only identify the degree of carbonation above/below $50 \%$ (i.e., the $\mathrm{pH}$ is higher/lower than 9) ${ }^{7}$ and the less carbonated location is impossible to be identified. In addition, XRD and TG are also widely employed to investigate the carbonation depth by characterizing the hydrated and carbonated products ${ }^{9}$. In principle, XRD is capable to investigate the crystal structure of carbonated products and thus determine the carbonation degree and carbonation front, and TG is dependent on the different decomposition temperature of $\mathrm{Ca}(\mathrm{OH})_{2}\left(420-600^{\circ} \mathrm{C}\right)^{14}$ and $\mathrm{CaCO}_{3}\left(440-800^{\circ} \mathrm{C}\right)^{15}$. Both XRD and TG could achieve quantitively analysis and have provided valuable information to assess the carbonation of the concrete ${ }^{10,16}$. However, both XRD and TG are traditional bulk analysis techniques ${ }^{17}$, and powder sample should be prepared prior to each test. As it is almost impractical to obtain powder at different depth at a microscale, high resolution spatial analysis on the carbonation depth is thereby rarely achieved, which is sometimes of significant importance. Apart from the above techniques, infrared (IR) spectroscopy ${ }^{8}$ and Raman spectroscopy have also been used to investigate the carbonation of cement paste, benefiting from their capability to follow identify the carbonated products in accordance with the characteristic peak of the $\mathrm{C}-\mathrm{O}$ stretching bond. These two techniques are discussed below.

Raman spectroscopy, a scattering based technology with high chemical fingerprint sensitivity, is a complementary technique to IR spectroscopy ${ }^{18}$. Raman spectroscopy has attracted increasing attention since it was first employed to characterize the cementbased materials in $1976^{19}$, which was followed by several systematical work on the spectrum of the main compounds of the cement ${ }^{20,21}$. In addition, Raman spectroscopy was also extensively applied to characterize of the deterioration products of cement-based materials under carbonation, sulfate, and alkali-silicate reactions attacks ${ }^{22}$. Overall, Raman spectroscopy has demonstrated its potential to study both hydration and

\footnotetext{
${ }^{1}$ Guangdong Provincial Key Laboratory of Durability for Marine Civil Engineering, Shenzhen Durability Centre for Civil Engineering, College of Civil and Transportation Engineering, Shenzhen University, Shenzhen, Guangdong, China. ${ }^{2}$ Institute of Technology for Marine Civil Engineering, Shenzhen Institute of Information Technology, Shenzhen, Guangdong, China. ${ }^{凶}$ email: wangyc_szu@126.com
} 
deterioration of cement-based materials in the literature. In comparison with IR spectroscopy, almost no preparation is required, and thus the negative effects induced by sample preparation could be minimized ${ }^{23}$. Furthermore, the spectra of the $\mathrm{CaCO}_{3}$, as the main carbonation products, obtained by Raman spectroscopy exhibits a much sharper peak corresponding to the $\mathrm{C}-\mathrm{O}$ vibration modes in $\mathrm{CO}_{3}$ group than that obtained by IR spectroscopy ${ }^{24}$. The Raman spectroscopy is thus more sensitive than IR spectroscopy to determine the carbonation evolution. Therefore, there is a few attempts to use Raman spectroscopy to evaluate the carbonation evolution and the obtained carbonation

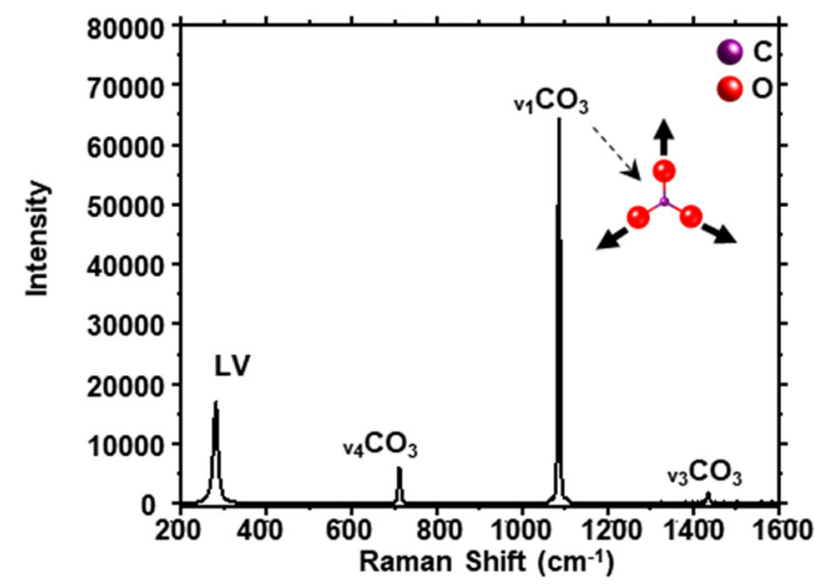

Fig. 1 Raman spectrum obtained from analytical grade $\mathrm{CaCO}_{3}$ powders. Raman spectrum showing typical characteristic peaks and associated vibrational modes. maps showed relative high resolution ${ }^{25-27}$. For instance, TorresCarrasco et al. $^{27}$ investigated the weathering effect on the deterioration of the anhydrous cement by using Raman spectroscopy, which main focused on the carbonation effect. In addition, Raman spectroscopy has followed the carbonation depth of carbonation reaction of lime paste successfully ${ }^{26}$. The ability of Raman spectroscopy to evaluate the spatial distribution of the carbonation products of Portland cement was further confirmed by Corvisier et al. ${ }^{25}$. It can be seen that using Raman spectroscopy to investigate the distribution of carbonation products in cement has shown great potential ${ }^{25,26}$, the quantitative analysis is still absent due to the lack of the correlation between the Raman intensity and content of the carbonation products.

Aim of the current work is thus to achieve the quantitative analysis of the carbonation products in hydrated cement paste by using Raman spectroscopy. To achieve this aim, standard reference specimens premixed with different dosages of $\mathrm{CO}_{3}{ }^{2-}$ were prepared and tested with Raman spectroscopy. Thereby, correlation between content of $\mathrm{CO}_{3}{ }^{2-}$ and intensity of the Raman characterization peak was established. To verify the accuracy of the established correlation as well as the feasibility of the quantitative analysis of the carbonation evolution, an investigation into the carbonation of the Portland cement was also completed. The obtained correlation was then used to characterize progress of carbonation in hardened cement paste exposed to an accelerated carbonation scenario, so as to explore in-depth mechanism of carbonation. Meanwhile, the most commonly used techniques, i.e., XRD and TG, were used to determine distribution of $\mathrm{CaCO} 3$ in the tested samples to further verify accuracy and suitability of the Raman mapping technique in studying progress of carbonation.

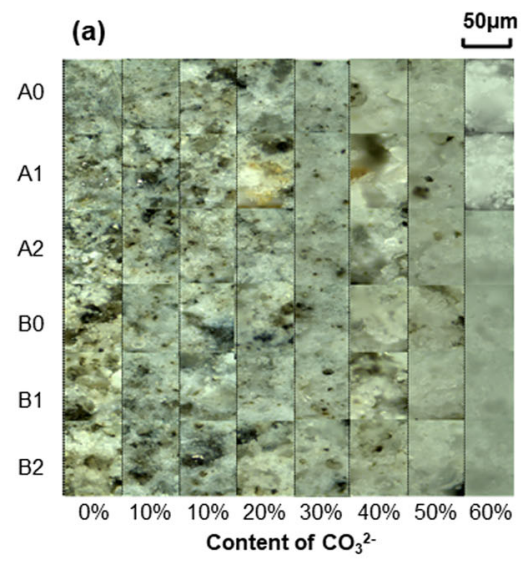

(b)

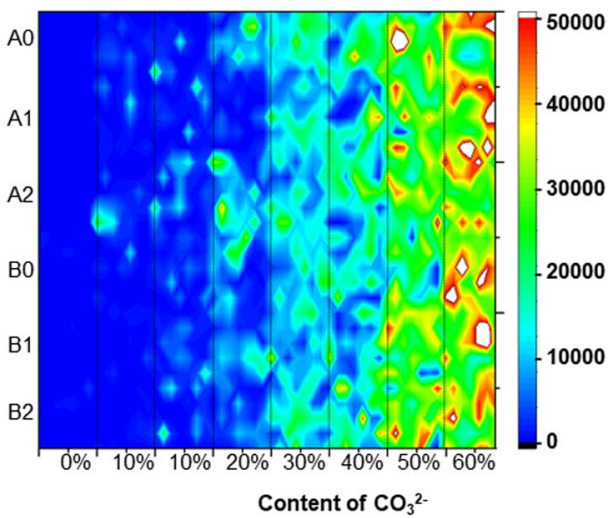

(c)

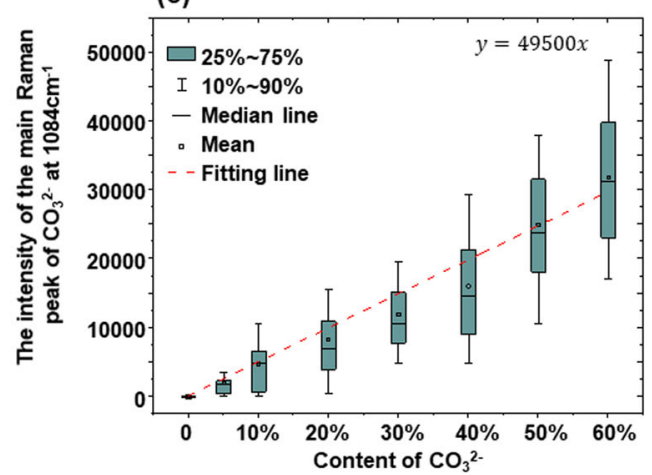

Fig. 2 Experimental results of the Raman spectroscopy measurements on the surface of the type (1) samples. a Appearance of test areas under optical microscope. b Mapping results of intensity of the $1084 \mathrm{~cm}^{-1}$ Rama peak (c) Box chart of Raman peak intensities against content of $\mathrm{CO}_{3}{ }^{2-}$ and the fitting result. 


\section{RESULTS}

\section{Building up the database for quantitative analysis}

Prior to the quantification analysis, a criterion to evaluate quantify the carbonation of cement paste is essential to be established. As the main carbonation product in cement paste is $\mathrm{CaCO}_{3}$, the carbonation can thus be linked to the content of the $\mathrm{CO}_{3}{ }^{2-}$ directly ${ }^{3}$. A typical Raman spectrum was obtained from analytical grade $\mathrm{CaCO}_{3}$ powders, as shown in Fig. 1. It can be seen that the spectrum present a strongest peak at $1084 \mathrm{~cm}^{-1}$, which should be assigned to the symmetric stretching of the $\mathrm{CO}_{3}$ group $\left(v_{1}\right)$ in $\mathrm{CaCO}_{3}$ as depicted in the spectrum ${ }^{28}$. Meanwhile, three minor peaks can also be identified at 281,711 , and $1435 \mathrm{~cm}^{-1}$, which are associated with $\mathrm{Ca}-\mathrm{O}$ lattice vibration mode, double degenerate in-plane bending mode and asymmetric stretching mode, respectively ${ }^{28-30}$. However, only this strongest peak can be observed when there is a small amount of $\mathrm{CO}_{3}{ }^{2-}$. Consequently, using the intensities of the peaks at 281,711 , and $1435 \mathrm{~cm}^{-1}$ as for quantification analysis might be not sensitive enough to identify the paste with low $\mathrm{CO}_{3}{ }^{2-}$ content. To improve the sensitivity to quantify $\mathrm{CO}_{3}{ }^{2-}$ with a minor content, the most intense peak at $1084 \mathrm{~cm}^{-1}$ was used as indicator to prove the existence of carbonated minerals and evaluate the carbonation degree in all the analyses ${ }^{26}$.

Figure 2 shows the experimental results of the Raman spectroscopy measurements on the surface of the type (1) samples which were premixed with different dosages of $\mathrm{CaCO}_{3}$. As explained above, three radom regions were selected in each sample and the images of these regions under optical microscope are displayed in Fig. 2a. It can be seen from the optical microscope images, mixes with a higher $\mathrm{CO}_{3}{ }^{2-}$ content presented a brighter and homogeneous color appearance, which is consistent with the color of $\mathrm{CaCO}_{3}$ powder ${ }^{31}$. Figure $2 \mathrm{~b}$ presents color mapping results revealing intensity of the $1084 \mathrm{~cm}^{-1}$ Raman peak $\left(v_{1} C_{3}\right)$ in the areas listed in Fig. 2a. Based on the differences of the mapping results, it can be easily derived that the intensity of the $1084 \mathrm{~cm}^{-1}$ Raman peak is associated with amount of the $\mathrm{CO}_{3}{ }^{2-}$ compounds.

Figure $2 \mathrm{c}$ presents a box chart revealing the correlation between the Raman peak intensity and the $\mathrm{CO}_{3}{ }^{2-}$ content of the test samples. Based on these data points, a linear relationship between $\mathrm{CO}_{3}{ }^{2-}$ content and intensity of the $1084 \mathrm{~cm}^{-1}$ peak is clearly illustrated as red dash line, which is similar to correlation between intensity of Raman peak and content of other compounds, e.g., salicylic acid and pharmaceutical compound, as reported elsewhere ${ }^{32,33}$. Therefore, the obtained fitting line, i.e.,

$y=49500 x$

(where $x$ is the $\mathrm{CO}_{3}{ }^{2-}$ content and $y$ is the intensity of the Raman peak at $1084 \mathrm{~cm}^{-1}$ ) with an $\mathrm{R}^{2}$ of 0.96 , can be used to convert Raman spectra signal to $\mathrm{CO}_{3}{ }^{2-}$ content in hardened cement paste samples. In such manner, potential of using the $1084 \mathrm{~cm}^{-1}$ Raman peak for quantification of $\mathrm{CO}_{3}{ }^{2-}$ content in hydrated cement paste is thus proved.

\section{Verification on feasibility of the established correlation to evaluate progress of carbonation}

To validate the accuracy and feasibility of the above established correlation for the carbonation process in a $\mathrm{CO}_{2}$ diffusion scenario, an attempt was made to use Raman spectroscopy to quantify the carbonation evolution of the cement paste under accelerated carbonation. TG measurements was also carried out to validate the quantification results obtained by Raman spectroscopy.

As stated, the Raman mapping measurements was applied on slice samples sliced from type (2) samples after 0d, 1d, 3d, 7d, 14d, $28 \mathrm{~d}$, and $56 \mathrm{~d}$ of accelerated carbonation. At the depth ranging from 0 to $10 \mathrm{~mm}$, Raman mapping analyses were conducted, and results were collected. By using the correlation obtained from Fig. 2c, statistic results from the $1084 \mathrm{~cm}^{-1}$ Raman peak can be

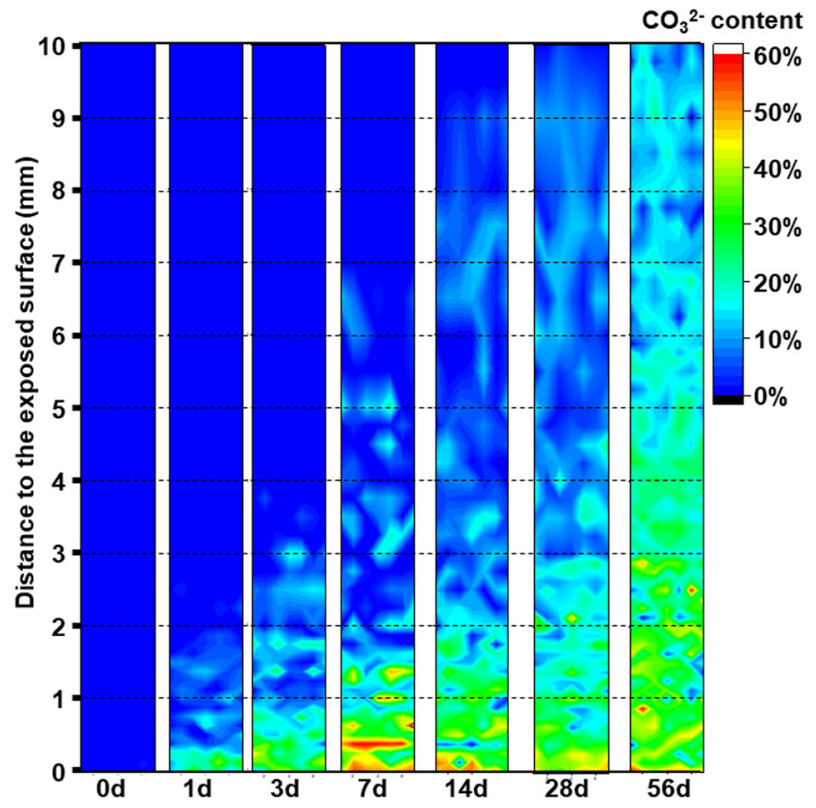

Fig. 3 Raman mapping showing the carbonation degree of the specimen after different ages of accelerated carbonation. Different colors representing the $\mathrm{CO}_{3}{ }^{2-}$ converting from the intensity of Raman peak at $1084 \mathrm{~cm}^{-1}$ by using the correlation obtained from Fig. 2c.

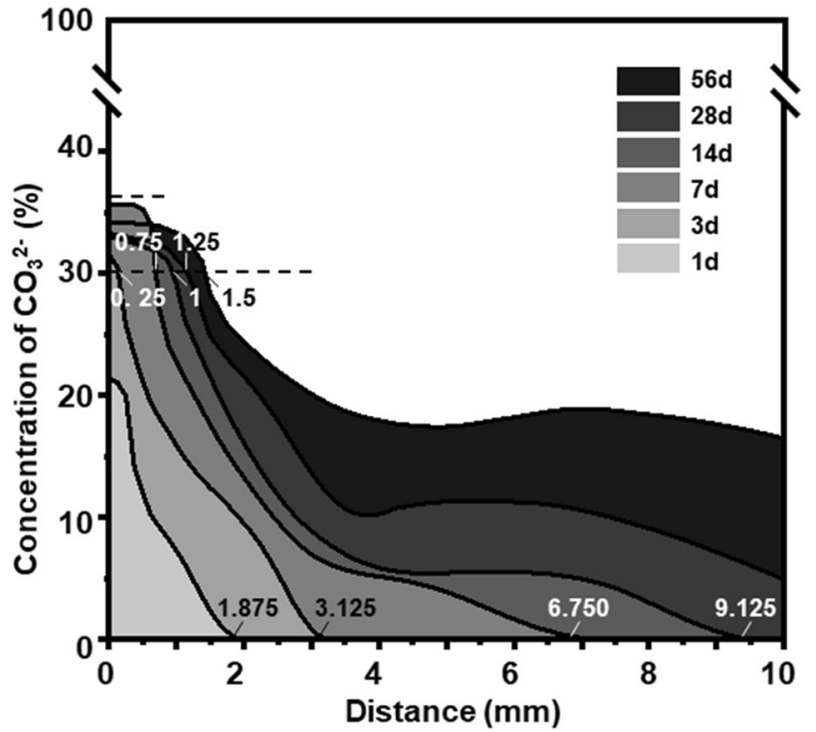

Fig. 4 The concentration of $\mathrm{CO}_{3}{ }^{2-}$ at different depth. An area graph illustrating the increase of the $\mathrm{CO}_{3}{ }^{2-}$ content with the time under accelerated carbonation against the distance to the exposure surface (the $\mathrm{CO}_{3}{ }^{2-}$ content at each depth is the averaged results of 8 points and the line was smoothed by Origin ${ }^{\mathrm{TM}}$ ).

converted to the distribution of $\mathrm{CO}_{3}{ }^{2-}$ content, as presented in Fig. 3. From the $\mathrm{CO}_{3}{ }^{2-}$ content mapping results, evolution of the carbonation process and the development of carbonation at certain location can be clearly observed.

As can be seen in Fig. 3, no $\mathrm{CO}_{3}{ }^{2-}$ was detected at 0 day, which confirms that good preparation and condition procedures were carried out prior to the accelerated carbonation. It can also be found that carbonation has started from the exposure surface, and the 
Table 1. Results obtained from Fig. 4, including depth of the carbonation front $\left(\mathrm{X}_{\mathrm{c}}\right)$, depth of the fully carbonated zone $\left(\mathrm{X}_{\mathrm{f}}\right)$, and the total $\mathrm{CO}_{3}{ }^{2-}$ content.

\begin{tabular}{|c|c|c|c|c|c|c|c|}
\hline & \multicolumn{7}{|c|}{ Duration } \\
\hline & Od & $1 d$ & $3 d$ & $7 d$ & $14 d$ & $28 d$ & $56 d$ \\
\hline $\mathrm{X}_{\mathrm{c}}(\mathrm{mm})$ & 0 & 1.875 & 3.125 & 6.750 & 9.125 & $\mathrm{~N} / \mathrm{A}$ & N/A \\
\hline $\mathrm{X}_{\mathrm{f}}(\mathrm{mm})$ & $\mathrm{N} / \mathrm{A}$ & N/A & 0.125 & 0.75 & 1 & 1.25 & 1.5 \\
\hline $\begin{array}{l}\text { Total } \mathrm{CO}_{3}{ }^{2-} \\
\text { content (\%) }\end{array}$ & 0.00 & 1.57 & 4.00 & 7.23 & 8.94 & 11.92 & 19.98 \\
\hline
\end{tabular}

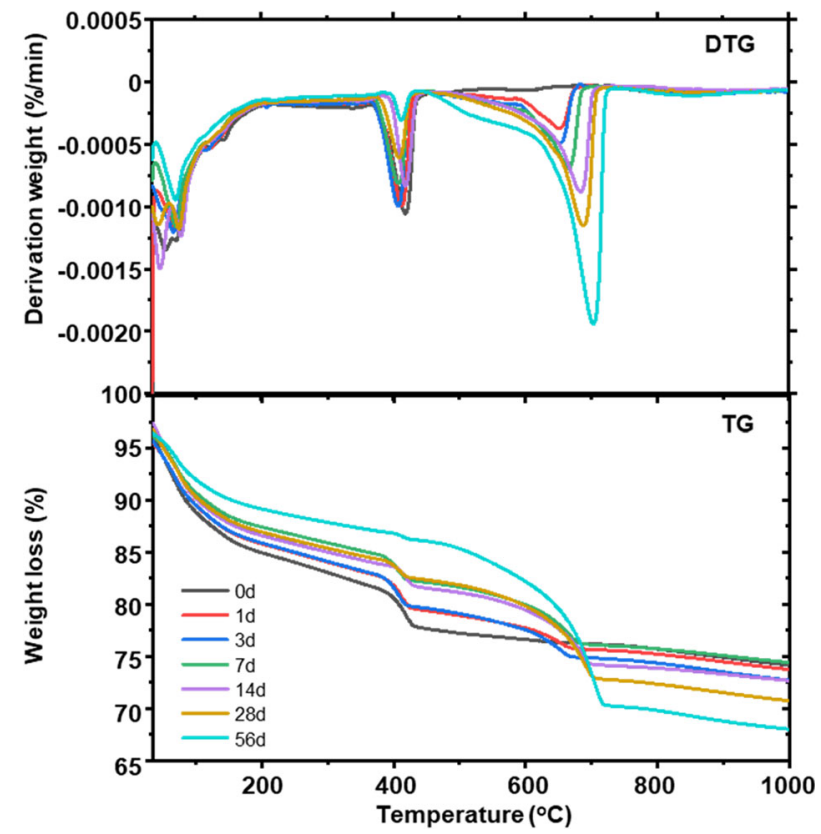

Fig. 5 Quantification of the $\mathrm{CO}_{3}{ }^{2-}$ content. TG and DTG results for the cement paste specimens.

carbonation front gradually increases with the time of accelerated carbonation. Although the distribution of the $\mathrm{CO}_{3}{ }^{2-}$ can be evaluated in Fig. 3, the exact quantities of the $\mathrm{CO}_{3}{ }^{2-}$ at all depths can be hardly compared so that the depth of the carbonation front and fully carbonated zone could be determined. Therefore, an area graph is depicted in Fig. 4 to present the contents of the $\mathrm{CO}_{3}{ }^{2-}$ at all depth for the specimens. The carbonation front could be easily found by looking at point where the $\mathrm{CO}_{3}{ }^{2-}$ content reaches 0 . The depth of the carbonation front has been labeled in Fig. 4 and recorded in Table 1. Based on the carbonation front, the diffusion coefficient could be calculated according to Eq. (2) (Where $X_{c}$ is the depth of carbonation front, $k$ is diffusion coefficient and $t$ is time). As the values of $X_{c}$ and $t$ are both available in Table 1, the diffusion coefficient can be calculated as 2.37. For the fully carbonated zone, the threshold of $\mathrm{CO}_{3}{ }^{2-}$ content should be established. In the literature, the content of the $\mathrm{CO}_{2}$ in the fully carbonated cement paste has been reported to range from $22 \%$ to $26 \% \%^{9,10}$. To convert $\mathrm{CO}_{2}$ content to $\mathrm{CO}_{3}{ }^{2-}$ content, Eq. (3) was employed (Where $\mathrm{C}_{\mathrm{CO}_{3}^{2-}}$ is the content of $\mathrm{CO}_{3}{ }^{2-} ; \mathrm{C}_{\mathrm{CO}_{2}}$ is the content of $\mathrm{CO}_{2} ; \mathrm{M}_{\mathrm{CO}^{2-}}$ is molecular mass of $\mathrm{CO}_{3}{ }^{2-}$ and $\mathrm{M}_{\mathrm{CO}_{2}}$ is molecular mass of $\mathrm{CO}_{2}$.). Based on calculation, the $\mathrm{CO}_{3}{ }^{2-}$ content should be between 30 and $36 \%$ for fully carbonated cement paste. The depth of the fully carbonated zone is thus defined as the point where $\mathrm{CO}_{3}{ }^{2-}$ content exceeds $30 \%$, which has been labeled in Fig. 4 and listed in Table 1. Furthermore, the overall carbonation degree could be evaluated by

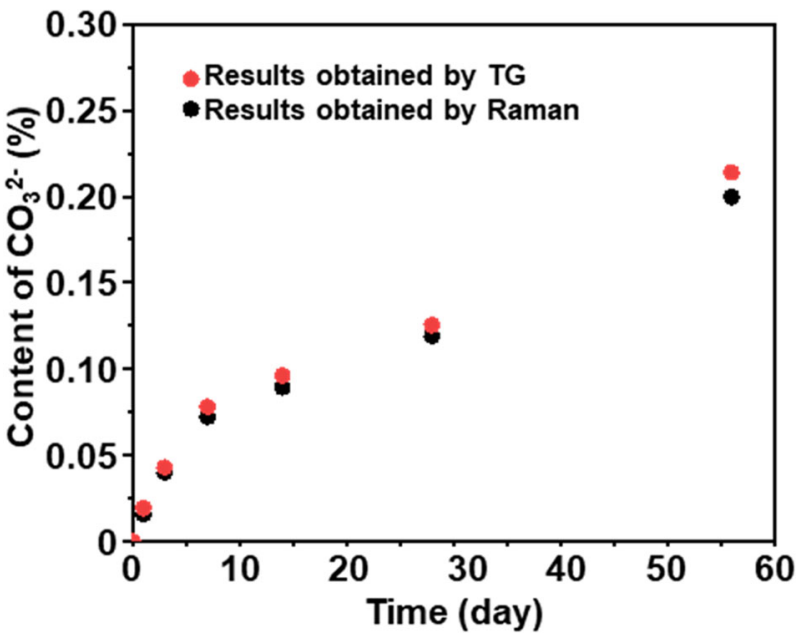

Fig. 6 Comparison between the results obtained by TG and Raman measurements. Plot of the content of $\mathrm{CO}_{3}{ }^{2-}$ obtained by Raman and TG measurements.

the total $\mathrm{CO}_{3}{ }^{2-}$ content within the specimen, which can be calculated by ratio of the area for each specimen to the whole area $(100 \% * 10 \mathrm{~mm})$ as depicted in Fig. 4 . The results have been listed in Table 1.

$X_{c}=k \sqrt{t}$

$C_{\mathrm{CO}_{3}^{2-}}=C_{\mathrm{CO}_{2}} \times \frac{M_{\mathrm{CO}_{3}^{2-}}}{M_{\mathrm{CO}_{2}}}$

The Raman spectroscopy has demonstrated its capacity to detect the distribution of the $\mathrm{CO}_{3}{ }^{2-}$ content over the sample surface, and this information can be used to evaluate the carbonation evaluation. To verify the above results, either comparing the similar results in the literature or carrying out complementary experiment is needed. However, it is almost impossible to compare the results with that reported in the literature because of the variation in experimental condition, such as the pretreatment, water/binder ratio and material, which has been proved to affect the carbonation depth significantly ${ }^{34}$. Complementary experiment, thermogravimetry analysis (TGA) was thus performed.

The TG measurements, as a conventional technique to quantify the content of $\mathrm{CO}_{3}{ }^{2-}$, have been performed to verify the Raman results. Figure 5 depicts the TG/DTG plots of cement paste specimens after $0,1,3,7,14,28$, and 56 days of accelerated carbonation. As explained earlier, DTG plots are employed to determine the decomposition intervals by inspecting the beginning and end of the peaks ${ }^{35}$. It can be seen that there are three peaks in Fig. 5, which are around 100,410 , and $700^{\circ} \mathrm{C}$. According to the temperature required for the decomposition of possible compounds in the carbonated cement paste specimens, these three peaks should be attributed to the evaporation of free water $\left(100{ }^{\circ} \mathrm{C}\right)$, dehydration of $\mathrm{Ca}(\mathrm{OH})_{2}\left(410^{\circ} \mathrm{C}\right)^{14,36}$ and decomposition of $\mathrm{CaCO}_{3}\left(700^{\circ} \mathrm{C}\right)^{10,37}$. As the purpose of TG measurements is to verify the quantification results, the peak for the decomposition of $\mathrm{CaCO}_{3}$ is analyzed only.

In the DTG curve, the peak at around $700{ }^{\circ} \mathrm{C}$ starts from the temperature $440{ }^{\circ} \mathrm{C}$ and continues till $800^{\circ} \mathrm{C}$, which is owing to the different polymorphs of $\mathrm{CaCO}_{3}{ }^{9,38,39}$. The weight loss corresponding to the decomposition of $\mathrm{CaCO}_{3}$ is thus evaluated between 440 and $800{ }^{\circ} \mathrm{C}$, and the exact ranges are determined according to the actual starting and ending points of the peak at each curve. As the weight loss results represent the weight of $\mathrm{CO}_{2}$, which are then converted to the $\mathrm{CO}_{3}{ }^{2-}$ by Eq. (3). To compare the total $\mathrm{CO}_{3}{ }^{2-}$ content obtained by TG and Raman measurements, they are 
plotted in Fig. 6. As can be seen that the content of $\mathrm{CO}_{3}{ }^{2-}$ obtained by TG and Raman measurements are almost the same. Therefore, the quantification results obtained by Raman measurements could be verified.

\section{DISCUSSION}

It might be worth noting that Raman results report a slightly less quantity of the $\mathrm{CO}_{3}{ }^{2-}$ content, especially for the specimen after 56 days of accelerated carbonation, which might be caused by the different polymorphs of the $\mathrm{CaCO}_{3}$ as explained above. It has been well-established that there are three polymorphs of $\mathrm{CaCO}_{3}$, i.e.,

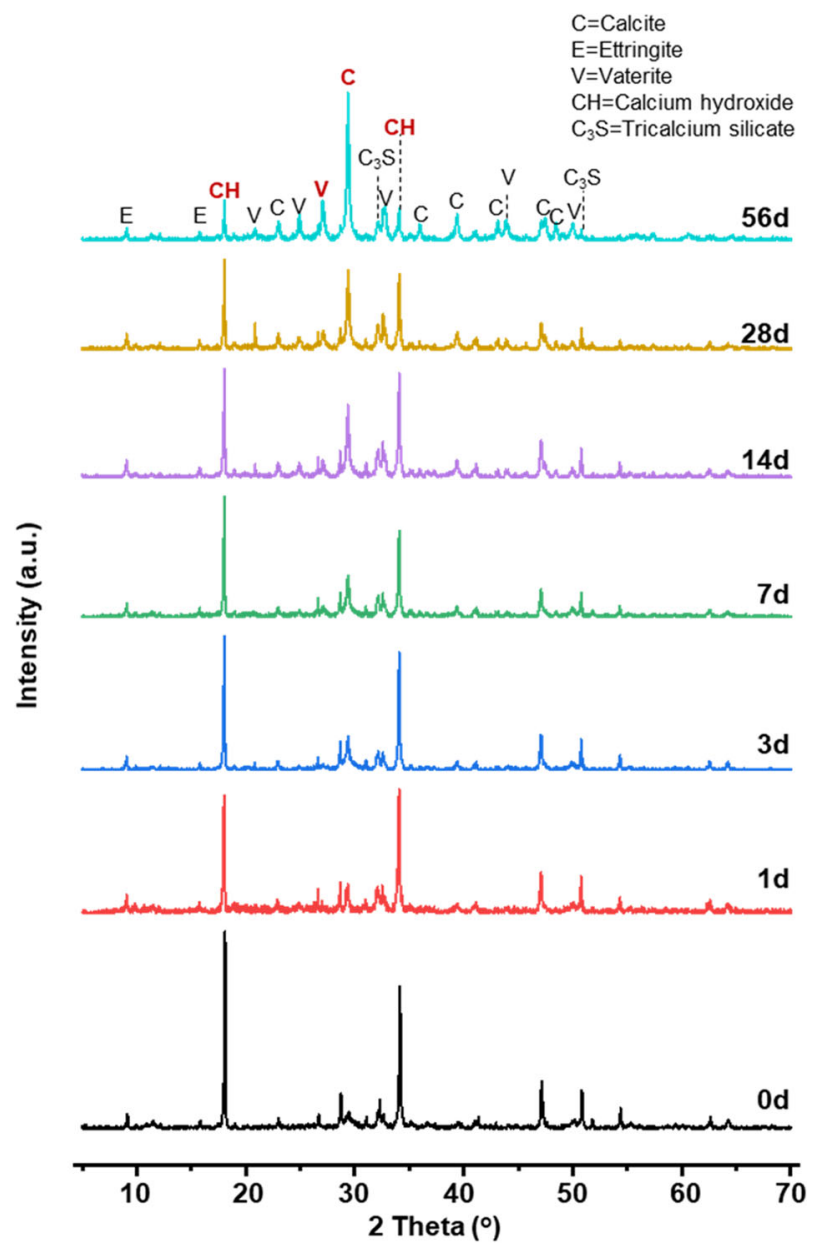

Fig. 7 Characterization of the chemical composition of carbonation products. XRD pattern of cement paste specimens after $0 \mathrm{~d}, 1 \mathrm{~d}$, $3 d, 14 d, 28 d$, and $56 d$ of accelerated carbonation. calcite, aragonite and vaterite, and calcite is known to be the main carbonation products ${ }^{40}$. Both calcite and aragonite pronounce a strongest peak at around $1084 \mathrm{~cm}^{-125}$. As explained in previously, quantitative analysis in present work is based on the intensity of the peak at $1084 \mathrm{~cm}^{-1}$, the existence of aragonite might not affect the quantification results. However, for vaterite, the main peak splits into a doublet at 1074 and $1090 \mathrm{~cm}^{-130,41}$. The presence of vaterite would thus potentially induce slight underestimation of carbonation degree. To verify the existence of vaterite, XRD measurements was performed for verification.

The XRD patterns of the cement paste specimens after $0,1,3,7$, 14,28 , and 56 days of accelerated carbonation have been depicted in Fig. 7. The assignments of the peaks have been well documented and labeled above the patterns. Among all the composition detected in the carbonated cement paste specimens, two polymorphs of the $\mathrm{CaCO}_{3}$ were found, i.e., calcite and vaterite. The presence of calcite could be confirmed by a strongest peak at $29.4^{\circ} 2 \theta$, along with many weak peaks as marked in Fig. $7^{42,43}$. Vaterite has its strongest peak at $27.0^{\circ} 2 \theta$ as well as other 4 peaks at $24.9^{\circ}, 32.8^{\circ}, 43.9^{\circ}$, and $50.0^{\circ} 2 \theta^{9,37}$. Therefore, the presence of the vaterite could be confirm. Based on the peak intensities, the quantity of the vaterite is neglectable before 3 days, which gradually increases after 7 days. In the meantime, the amount of calcite, as the main carbonation products, rises much more dramatically as shown in the XRD pattern (Fig. 7). Therefore, the $\mathrm{CO}_{3}{ }^{2-}$ content results obtained by Raman spectroscopy is representative to assess the carbonation degree, although the existence of vaterite may induce the minor underestimation.

Overall, in present work, the correlation between the Raman peak intensity and the content of $\mathrm{CO}_{3}{ }^{2-}$ were established Initially by a linear equation: $y=49500 x$. The established correlation was employed to study the accelerated carbonation of the cement paste in a $\mathrm{CO}_{2}$ diffusion scenario. The results clearly show the distribution and quantity of the carbonation products. In addition, the accuracy of the obtained quantification results by Raman spectroscopy were confirmed by TG results. Overall, the feasibility of employing the Raman spectroscopy for quantitative analysis of the cement paste carbonation has been fully demonstrated.

\section{METHOD}

\section{Material and sample preparation}

In this study, two types of samples were manufactured in lab, viz. (1) cylindrical hardened cement paste, with a dimension of $\varphi 20 \mathrm{~mm} \times 10 \mathrm{~mm}$, as depicted in Fig. 8a, and (2) a $\varphi 28 \mathrm{~mm} \times 150 \mathrm{~mm}$ cement sample as depicted in Fig. 8b. The previous group of samples involving eight groups of hardened cement paste samples containing $0 \%, 5 \%, 10 \%, 20 \%, 30 \%, 40 \%, 50 \%$ and $60 \%$ of $\mathrm{CO}_{3}{ }^{2-}$, respectively, which was achieved by adding analytical grade calcium carbonate during mix. Two groups of type (1) specimens were prepared to improve the reproductivity of the experimental results, namely group A and group B. To facilitate a reasonable hydration of cement and a meaningful carbonation speed, a water/binder $(\mathrm{w} / \mathrm{b})$ ratio of 0.45 was designated for all the eight mixes. For the latter type of sample, the cement (a)

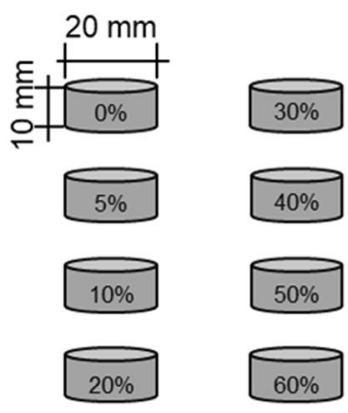

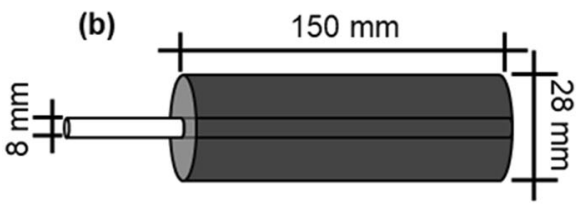

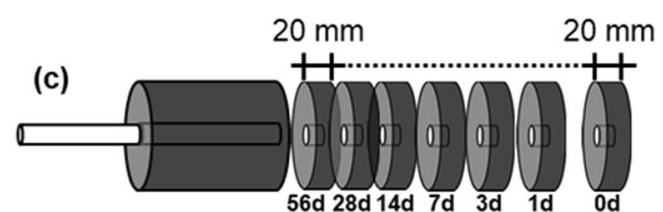

Fig. 8 Schematic diagram for the sample preparation. a Standard cement specimens. b Cement paste specimens. c Slices of the cement paste specimen. 


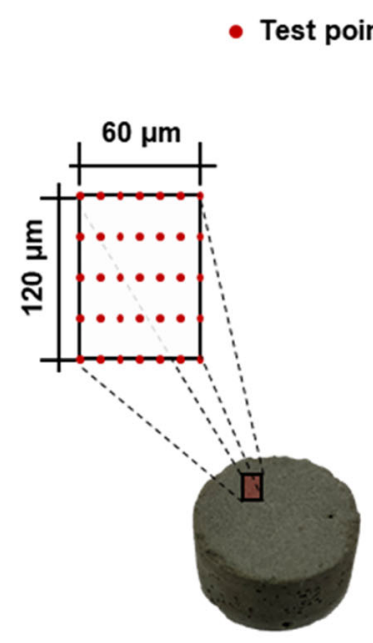

(a)

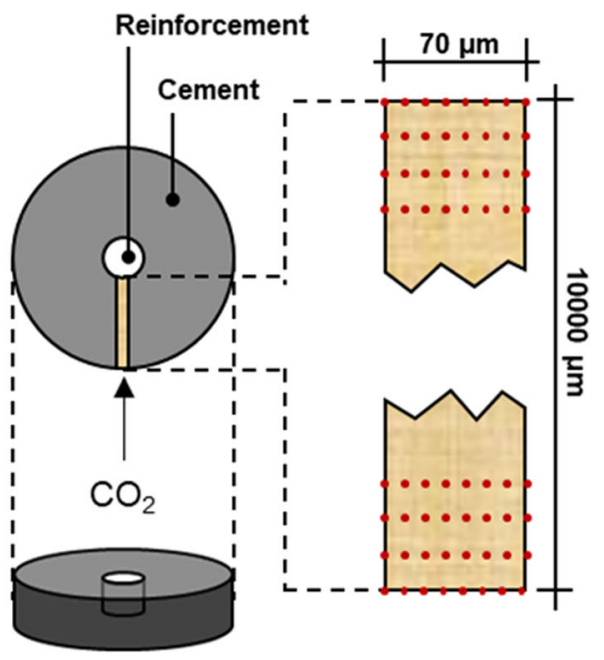

(b)

Fig. 9 Diagrams showing the test points for data collection. a Test points for type 1 specimens. b Test points for type 2 specimens.

paste cover was a hydrated Portland cement with a w/b of 0.45 . The procedure for mixing pastes followed ASTM C $305^{44}$. The porosity of all samples should be consistent with that reported in the literature.

After cast, all the samples were cured in a vacuum dryer for $24 \mathrm{~h}$ to avoid carbonation. After curing, type (1) samples were ready for the Raman spectroscopy measurements; while type (2) samples were placed in a carbonation chamber with a condition at $\sim 74 \% \mathrm{RH}, 20 \% \mathrm{CO}_{2}, 20^{\circ} \mathrm{C}$. Prior to carbonation of the type (2) samples, two ends of the specimen were sealed to make sure that only the side of the cylinder was exposed to $\mathrm{CO}_{2}$. At the age of $0,1,3,7,14,28$, and 56 days of the accelerated carbonation, as depicted in Fig. 8c, a $20 \mathrm{~mm}$ long cylinder sample was cut off to test the development of carbonation with Raman spectroscopy, TG and XRD. It is worth pointing out that the slice obtained at 0 day was used to verify that no carbonation happened during the sample preparation.

\section{Raman spectroscopy}

Raman spectra were acquired by using a Reinshaw inVia Raman spectroscope, which is equipped with a $532 \mathrm{~nm}$ laser and a charged coupled device detector. Laser was focused via a Lecia $\times 50$ (N.A. $=0.55$ ) into a spot size of $1.40 \mu \mathrm{m}$ in diameter on test samples. To avoid possible decomposition of carbonation products under applied energy, power of the tests was limited within $0.82 \mathrm{~mW}$. All the spectra were recorded with an exposure time of $10 \mathrm{~s}$ and two accumulations to improve the signal-tonoise ratio.

For the type (1) sample, three regions with an area of $150 \times 60 \mu \mathrm{m}$ were selected randomly form group $A$ and group $B$, named A0-A2 and B0-B2. In each region, 35 spectra forming a matrix of $7 \times 5$ were collected, as depicted in Fig. 9a. For the sliced disc specimens, the Raman spectroscopy was collected from a threadlike testing area ranging from surface to a depth of $10 \mathrm{~mm}$ and covered a width of $70 \mu \mathrm{m}$. In each of this area, 640 spectra forming a matrix of $8 \times 80$ were collected and the intervals of the analyses for the parallel and vertical directions were 10 and $125 \mu \mathrm{m}$, respectively, as shown in Fig. 9b.

The Raman spectra obtained from cement are always accompanied with unwanted sloping background, which may be caused by the intrinsic fluorescence as well as the incorporation of optics ${ }^{45,46}$. The background is thus subtracted by using WIRE 5.1 via an "intelligent fitting" process with a polynomial value of 11 .

\section{X-ray diffraction (XRD) and thermogravimetry (TG) analyses}

After the Raman measurements, the disc specimens were crushed into powder with particle size of lower than $70 \mu \mathrm{m}$. Subsequently, the powder was immediately analyzed with TG and XRD for their $\mathrm{CaCO}_{3}$ contents and composition of the carbonation products, so as to verify the quantification results obtained by Raman spectroscopy.

The TG measurements were carried out by using a TA SQT-Q600, and the temperature range was from $30^{\circ} \mathrm{C}$ to $1000^{\circ} \mathrm{C}$ with a heating rate of $10^{\circ} \mathrm{C} /$ min. The XRD measurements were carried out using a Bruker D8 Advance diffractometer. A scanning range between 5 and $70^{\circ}$ with a scanning rate of $0.02 \%$ step was selected.

\section{DATA AVAILABILITY}

All the data associated with this study are available from the corresponding author upon request.

Received: 6 February 2021; Accepted: 4 June 2021; Published online: 25 June 2021

\section{REFERENCES}

1. Aïtcin, P.-C. \& Flatt, R. J. Science and Technology of Concrete Admixtures. Vol. 339 (Woodhead Publishing, 2015).

2. Liu, J. et al. Degradation of fly ash concrete under the coupled effect of carbonation and chloride aerosol ingress. Corros. Sci. 112, 364-372 (2016).

3. Papadakis, V., Fardis, M. \& Vayenas, C. Effect of composition, environmental factors and cement-lime mortar coating on concrete carbonation. Mater. Struct. 25, 293-304 (1992).

4. Huet, B., L'Hostis, V., Miserque, F. \& Idrissi, H. Electrochemical behavior of mild steel in concrete: Influence of $\mathrm{pH}$ and carbonate content of concrete pore solution. Electrochim. Acta 51, 172-180 (2005).

5. Gonzalez, J. A. et al. Some questions on the corrosion of steel in concrete. Part II: corrosion mechanism and monitoring, service life prediction and protection methods. Mater. Struct. 29, 97-104 (1996).

6. Thiery, M., Villain, G., Dangla, P. \& Platret, G. Investigation of the carbonation front shape on cementitious materials: effects of the chemical kinetics. Cem. Concr. Res. 37, 1047-1058 (2007).

7. Chang, C.-F. \& Chen, J.-W. The experimental investigation of concrete carbonation depth. Cem. Concr. Res. 36, 1760-1767 (2006).

8. Lo, Y. \& Lee, H. M. Curing effects on carbonation of concrete using a phenolphthalein indicator and Fourier-transform infrared spectroscopy. Build. Environ. 37, 507-514 (2002).

9. Shah, V., Scrivener, K., Bhattacharjee, B. \& Bishnoi, S. Changes in microstructure characteristics of cement paste on carbonation. Cem. Concr. Res. 109, 184-197 (2018).

10. Villain, G., Thiery, M. \& Platret, G. Measurement methods of carbonation profiles in concrete: Thermogravimetry, chemical analysis and gammadensimetry. Cem. Concr. Res. 37, 1182-1192 (2007).

11. Lawrence, R. M. H., Mays, T. J., Walker, P. \& D'Ayala, D. Determination of carbonation profiles in non-hydraulic lime mortars using thermogravimetric analysis. Thermochim. Acta 444, 179-189 (2006).

12. Lee, H. J., Kim, D. G., Lee, J. H. \& Cho, M. S. A study for carbonation degree on concrete using a phenolphthalein indicator and fourier-transform infrared spectroscopy. Int. J. Civ. Environ. Eng. 34, 184-190 (2012). 
13. Chinchón-Payá, S., Andrade, C. \& Chinchón, S. Indicator of carbonation front in concrete as substitute to phenolphthalein. Cem. Concr. Res. 82, 87-91 (2016).

14. Criado, Y. A., Alonso, M. N. \& Abanades, J. C. Kinetics of the $\mathrm{CaO} / \mathrm{Ca}(\mathrm{OH}) 2$ hydration/dehydration reaction for thermochemical energy storage applications. Ind. Eng. Chem. Res. 53, 12594-12601 (2014).

15. Ramachandran, D., Uthaman, S. \& Vishwakarma, V. Studies of carbonation process in nanoparticles modified fly ash concrete. Constr. Build. Mater. 252, 119127 (2020).

16. Liu, W., Li, Y.-Q., Tang, L.-P. \& Dong, Z.-J. XRD and 29Si MAS NMR study on carbonated cement paste under accelerated carbonation using different concentration of CO2. Mater. Today Commun. 19, 464-470 (2019).

17. Nasrazadani, S. \& Hassani, S. Handbook of Materials Failure Analysis with Case Studies from the Oil and Gas Industry. Vol. 2 (Butterworth-Heinemann, 2016).

18. Park, K. \& Cho, M. Time-and frequency-resolved coherent two-dimensional IR spectroscopy: its complementary relationship with the coherent two-dimensional Raman scattering spectroscopy. J. Chem. Phys. 109, 10559-10569 (1998).

19. Bensted, J. Uses of Raman Spectroscopy in cement chemistry. J. Am. Ceram. Soc. 59, 140-143 (1976)

20. Conjeaud, M. \& Boyer, H. Some possibilities of Raman microprobe in cement chemistry. Cem. Concr. Res. 10, 61-70 (1980).

21. Potgieter-Vermaak, S. S., Potgieter, J. H. \& Van Grieken, R. The application of Raman spectrometry to investigate and characterize cement, Part I: a review. Cem. Concr. Res. 36, 656-662 (2006).

22. Tang, C., Ling, T.-C. \& Mo, K. H. Raman spectroscopy as a tool to understand the mechanism of concrete durability—a review. Constr. Build. Mater. 268, 121079 (2021)

23. Kuptsov, A. \& Zhizhin, G. N. Handbook of Fourier Transform Raman and Infrared Spectra of Polymers. Vol. 1 (Elsevier, 1998).

24. Fong, M. Y. \& Nicol, M. Raman spectrum of calcium carbonate at high pressures. J. Chem. Phys. 54, 579-585 (1971).

25. Corvisier, J. et al. Raman mapping and numerical simulation of calcium carbonates distribution in experimentally carbonated Portland-cement cores. Eur. J. Mineral. 22, 63-74 (2010).

26. Ševčík, R. et al. Micro-Raman spectroscopy investigation of the carbonation reaction in a lime paste produced with a traditional technology. J. Raman Spectrosc. 47, 1452-1457 (2016)

27. Torres-Carrasco, M. et al. New insights in weathering analysis of anhydrous cements by using high spectral and spatial resolution Confocal Raman Microscopy. Cem. Concr. Res. 100, 119-128 (2017).

28. Nakamoto, K. Handbook of Vibrational Spectroscopy. Vol. 3 1872-1892 (John Wiley \& Sons, 2006).

29. Wehrmeister, U. et al. Amorphous, nanocrystalline and crystalline calcium carbonates in biological materials. J. Raman Spectrosc. 42, 926-935 (2011).

30. Wehrmeister, U., Soldati, A., Jacob, D., Häger, T. \& Hofmeister, W. Raman spectroscopy of synthetic, geological and biological vaterite: a Raman spectroscopic study. J. Raman Spectrosc. 41, 193-201 (2010).

31. Eloneva, S., Mannisto, P., Said, A., Fogelholm, C. J. \& Zevenhoven, R. Ammonium salt-based steelmaking slag carbonation: precipitation of $\mathrm{CaCO} 3$ and ammonia losses assessment. GREENH GASES 1, 305-311 (2011).

32. Eksi-Kocak, H. et al. Quantification and spatial distribution of salicylic acid in film tablets using FT-Raman mapping with multivariate curve resolution. Asian J. Pharm. Sci. 13, 155-162 (2018).

33. Langkilde, F. W., Sjöblom, J., Tekenbergs-Hjelte, L. \& Mrak, J. Quantitative FTRaman analysis of two crystal forms of a pharmaceutical compound. J. Pharm. Biomed. Anal. 15, 687-696 (1997).

34. Atiş, C. D. Accelerated carbonation and testing of concrete made with fly ash Constr. Build. Mater. 17, 147-152 (2003).

35. Font, R. Handbook of Thermal Analysis and Calorimetry. Vol. 9 (Elsevier Science B. V., 2018).

36. Irabien, A., Viguri, J. R. \& Ortiz, I. Thermal dehydration of calcium hydroxide. 1. Kinetic model and parameters. Ind. Eng. Chem. Res. 29, 1599-1606 (1990).

37. Liu, W. et al. Changes in chemical phases and microscopic characteristics of fly ash blended cement pastes in different $\mathrm{CO} 2$ concentrations. Constr. Build. Mater 257, 119598 (2020)

38. Šauman, Z. Carbonization of porous concrete and its main binding components. Cem. Concr. Res. 1, 645-662 (1971).

39. Borges, P. H. R., Costa, J. O., Milestone, N. B., Lynsdale, C. J. \& Streatfield, R. E. Carbonation of $\mathrm{CH}$ and $\mathrm{C}-\mathrm{S}-\mathrm{H}$ in composite cement pastes containing high amounts of BFS. Cem. Concr. Res. 40, 284-292 (2010).
40. Shi, C., Tu, Z., Guo, M.-Z. \& Wang, D. Sustainable and Nonconventional Construction Materials using Inorganic Bonded Fiber Composites. Vol. 12 (Woodhead Publishing, 2017).

41. Martinez-Ramirez, S. et al. Micro-Raman spectroscopy applied to depth profiles of carbonates formed in lime mortar. Cem. Concr. Res. 33, 2063-2068 (2003).

42. Rostami, V., Shao, Y., Boyd, A. J. \& He, Z. Microstructure of cement paste subject to early carbonation curing. Cem. Concr. Res. 42, 186-193 (2012).

43. Zhang, D., Cai, X. \& Jaworska, B. Effect of pre-carbonation hydration on long-term hydration of carbonation-cured cement-based materials. Constr. Build. Mater. 231, 117122 (2020).

44. ASTM. C305-20 Standard Practice For Mechanical Mixing of Hydraulic Cement Pastes and Mortars of Plastic Consistency. (ASTM International, 2006).

45. Cadusch, P., Hlaing, M., Wade, S., McArthur, S. \& Stoddart, P. Improved methods for fluorescence background subtraction from Raman spectra. J. Raman Spectrosc. 44, 1587-1595 (2013).

46. Yue, Y., Wang, J. J., Basheer, P. A. M., Boland, J. J. \& Bai, Y. A Raman spectroscopy based optical fibre system for detecting carbonation profile of cementitious materials. Sens. Actuators B Chem. 257, 635-649 (2018).

\section{ACKNOWLEDGEMENTS}

Authors would like to appreciate financial support provided by National Natural Science Foundation of China (Nos. 52078301, 51978408), Guangdong Basic and Applied Basic Research Foundation (No. 2019A1515012014). Technique supports from Guangdong Provincial Key Laboratory of Durability for Marine Civil Engineering (SZU) No. 2020B1212060074.

\section{AUTHOR CONTRIBUTIONS}

T.M. conceived the idea and wrote the draft of paper. T.M. and Y.L. conducted the experiments and paper revision. WeiL. and WeiwenL. contribute to the data analysis of the TG measurements and overall formatting of the paper. W.L. and F.X. contributed to establishing the experimental approaches and figure plotting. Z.D. and Q.G. contributed to data analysis for the Raman measurements. Y.W. supervised the whole project and revised the paper.

\section{COMPETING INTERESTS}

The authors declare no competing interests.

\section{ADDITIONAL INFORMATION}

Correspondence and requests for materials should be addressed to Y.W.

Reprints and permission information is available at http://www.nature.com/ reprints

Publisher's note Springer Nature remains neutral with regard to jurisdictional claims in published maps and institutional affiliations. Attribution 4.0 International License, which permits use, sharing, adaptation, distribution and reproduction in any medium or format, as long as you give appropriate credit to the original author(s) and the source, provide a link to the Creative Commons license, and indicate if changes were made. The images or other third party material in this article are included in the article's Creative Commons license, unless indicated otherwise in a credit line to the material. If material is not included in the article's Creative Commons license and your intended use is not permitted by statutory regulation or exceeds the permitted use, you will need to obtain permission directly from the copyright holder. To view a copy of this license, visit http://creativecommons. org/licenses/by/4.0/.

(c) The Author(s) 2021 